\title{
Entre o Corpo e a Alma: a possibilidade do conhecimento das Formas e o contexto dramático em Fédon
}

\author{
Frederico Duarte Pires de Sousa *
}

Resumo: Em Fédon vemos a morte ser assumida como o fim da filosofia. É também neste mesmo diálogo que Platão nos narra a morte de Sócrates, seu importante herói dramático e porta-voz filosófico. Será, portanto, entre estas duas dimensões do diálogo platônico em questão, uma teorética e outra dramática, que nesta reflexão nos situaremos. Nosso intuito é revistar esta importante obra do pensamento de Platão tendo como fim considerar em que medida a Doutrina das Formas aqui é convocada em uma profunda relação com o contexto dramático e narrativo do diálogo.

Palavras-Chave: Doutrina das Formas; Fédon; Morte; Platão.

\section{Between the Body and the Soul: the possibility of the knowledge of the Forms and the dramatic context in Phaedo}

\begin{abstract}
In Phaedo we see the death being assumed as the telos of philosophy. It is also in this same dialogue that Plato presents to us the death of Socrates, his important dramatic hero and philosophical spokesman. It will be, therefore, between these two dimensions of the Platonic dialogue in debate, a theoretical one and a dramatic one, that in this reflection we will place ourselves. Our purpose is to review this important work of Platonic thought in order to consider in what extent the Doctrine of Forms here is convocaded in a deep relation with the dramatic and narrative context of the dialogue.
\end{abstract}

Keywords: Doctrine of Forms; Phaedo; Death; Plato.

O diálogo Fédon, sabe-se, ocupa um lugar privilegiado no interior do corpus platonicum. É a um só tempo tanto o último quanto o primeiro momento dramático ${ }^{1}$ de

\footnotetext{
* Mestre em Comunicação pela Universidade Federal de Goiás (UFG) com doutorado em andamento em Filosofia pela mesma Universidade.E-mail: fredericodsousa@gmail.com.
} 
Sócrates na obra platônica: em uma profunda relação dialética, Platão nos narra, de um lado, a derradeira passagem de seu herói filosófico, bem como, por outro, nos remete à primeira fase do itinerarium intelectual de seu Sócrates - e assim, é certo que antes mesmo de Parmênides, ao menos do ponto de vista do desenvolvimento de uma narrativa que toma Sócrates como herói dramático, poderíamos situar o relato que aparece em Fédon a partir de $96 \mathrm{~b}$ no qual Sócrates nos conta de seus primeiros anos de aprendizagem e do modo como a doutrina das ideias lhe apareceu como o ponto de partida da saga filosófica de Sócrates. Sem embargo, Fédon é importante não apenas pelo seu alto valor narrativo - já que nos apresenta a morte da persona socrática -, mas, o que é natural, principalmente pelas múltiplas teses teoréticas ali estabelecidas: a imortalidade da alma, a oposição entre corpo e alma, a caracterização das Formas, o papel causal e o problema da cognoscibilidade destas, e, não menos importante, a morte como realização da filosofia. A nossa tese, porém, é de que em Fédon - mais do que em qualquer outro diálogo platônico aquilo que é apresentado na dimensão narrativa torna-se diretamente relevante para aquilo que se propõe na dimensão teórica: afinal, a quem mais poderia ser interessante demonstrar a imortalidade da alma e a bem-aventurança dos filósofos no post mortem do que justamente àquele que se encontra na iminência da própria morte? Como bem nos diz o Sócrates de Platão: "Talvez, mesmo, seja a quem se encontra no ponto de imigrar para o outro mundo que compete investigar acerca dessa viagem e dizer como será preciso imaginá-la." (Féd. 61e 1-3, grifos nossos).

$1 \quad$ No sentido de ser tanto a primeira quanto a última cena da personagem na longa narrativa platônica. Por questões metodológicas próprias aos interesses desta reflexão - e para evitar um eruditismo que nos faria apenas navegar a esmo em busca de conceitos -, assumimos os termos "drama", "dramático" ou ainda "contexto dramático" em sentido próximo ao de "narrativa". Para nós, mais do que o debate teórico sobre o conceito de "drama", nos interessa entender como um texto narrativo/dramático/ficcional desvela aquilo que Paul Ricoeur (1995) chama de "o mundo do texto" ou ainda a "coisa do texto", isto é, a autonomia semântica do discurso que por meio das ações narradas é capaz de dizer um mundo possível. Nas palavras do filósofo francês: "O texto fala de um mundo possível e de um modo possível de alguém nele se orientar. As dimensões deste mundo são propriamente abertas e descortinadas pelo texto." (RICOEUR, 1995, p.132). David Pellauer ainda acrescenta: “[...] como toda narrativa, a ficção nos apresenta um mundo do texto no qual se supõe o desenrolar da história e este é um mundo que podemos nós mesmos imaginar habitando. Daí, com base nisso, a ficção narrativa é uma forma de ver o mundo diferentemente, mas também de modos que podem ser verdadeiros acerca do mundo tal como ele efetivamente é ou pode ser.” (PELLAUER, 2009, p.107). É, afinal, do mundo possível - ou ao menos de parte dele - no qual o Sócrates de Platão vive sua aventura filosófica de que aqui nos ocupamos. Ricoeur é categórico:"Efectivamente, o que é que num texto se deve compreender - e, por conseguinte, apropriar? Não é a intenção do autor, que se encontra supostamente oculta por detrás do texto; não é a situação histórica comum ao autor e aos seus leitores originais; não são as expectações ou sentimentos desses leitores originais; não é sequer a autocompreensão que de si tinham como fenômenos históricos e culturais. Aquilo de que importa apropriar-se é o sentido do próprio texto, concebido de um modo dinâmico como a direção do pensamento aberta pelo texto. Por outras palavras, aquilo de que importa apropriar-se nada mais é do que o poder de desvelar um mundo que constitui a referência do texto." (RICOEUR, 1995, p.136). Para mais informações: Cf.: RICOEUR, Paul. Teoria da Interpretação. Introdução e comentários de Isabel Gomes. Lisboa: Porto Editora, 1995. 
Nos permitamos um exemplo que parece justificar nossa proposta: após Sócrates ter dito à Cebes (em Féd. 61c) que este deveria dizer a Eveno que lhe sugeria que o seguisse o quanto antes, caso fosse sábio, em sua imigração, diante do estranhamento de seus discípulos a uma tal sugestão, Sócrates inicia uma breve defesa de sua fala (Féd. 61e 62c) ao que Cebes (Féd. 62d - 62e) percebe algumas contradições entre o argumento, ainda incompleto, e a sugestão socrática a Eveno; o ponto que aqui nos interessa é a defesa que a respeito da crítica de Cebes tecerá Símias - diz Símias: “A meu ver, o argumento de Cebes vai dirigido contra ti, por aceitares à ligeira a ideia de deixar-nos, e também aos amos cuja superioridade és o primeiro a declarar." (Féd. 62e 7-10) Ou seja: é justamente a situação na qual Sócrates se encontra, que explica, para Símias, o abuso que ele estaria, em tese, fazendo de sua argumentação em defesa da Morte.

Portanto, logo percebe-se, a morte e a busca por uma demonstração da imortalidade da alma é a chave temática em torno da qual todo o debate, seja em seus aspectos teoréticos, seja sem seus aspectos dramáticos/narrativos, gira - contudo, é precisamente através do contexto dramático que tal chave passa ser posta em debate. Porém, não obstante a importância desta chave temática no interior da obra, o diálogo Fédon tornou-se mais conhecido na tradição pela defesa e caracterização daquilo que na filosofia platônica é tomado como sendo a Doutrina das Formas. E sem dúvidas, dada a importância que esta doutrina ocupa na evolução posterior do pensamento de Platão e em relação a que herança socrática ela ascende enquanto resposta, não podemos negar a pertinência de tal obscurecimento dos demais níveis teoréticos e dramáticos presentes em Fédon em favor das Formas. Afinal, conforme nos diz Michael Erler (2013, p.221), aquilo que caracterizaria, de fato, o verdadeiro filósofo, para Platão (Rep. 502c - 518c), seria o conhecimento das Formas (ideias).

As Formas, além de nos oferecerem o objeto do conhecimento cujo qual deve o filósofo perseguir, também nos permitem compreender em que medida o pensamento platônico caminha - de forma clara - para além da herança socrática. Se seguirmos a leitura de Richard Kraut (2013, p.24) e endossarmos que a obra platônica possa ser dividida em três períodos distintos, sendo o período intermediário o período em que Platão começa a de fato apresentar suas concepções, a compreensão da Doutrina das Formas se torna conditio sine qua non para o entendimento do pensamento platônico propriamente dito. É verdade que como bem coloca Richard Kraut: "Sócrates proporcionou a Platão a ideia fundamental de que é vital para nosso bem-estar descobrir o único fator unificador 
em nosso uso diverso de termos morais.” (KRAUT, 2013, p. 23). Percebemos assim, sobretudo em vistas da Doutrina das Formas, o quão importante foi ao pensamento platônico o fato de Sócrates ter insistido na necessidade de se buscar conhecer aquilo que unificaria os diversos usos que fazemos dos termos morais, como a "virtude", a "coragem", e inclusive o "conhecimento". Sócrates levou Platão na direção dos conceitos universais. Porém é também aqui que Platão se aparta de Sócrates. Nem mesmo seria imprudência dizer que as Formas podem ser assumidas como uma superação, especificamente platônica, das aporias socráticas a respeito dos conceitos universais (por exemplo, o diálogo Mênon - composto em tese no fim da primeira fase do pensamento platônico -, a despeito de uma intensa busca por uma definição de virtude, é concluído de maneira aporética uma vez que não se encontra ali presente o recurso às Formas). A partir de então, são elas, as Formas, que tornam possível que apesar da diversidade dos casos particulares, uma multiplicidade destes possa ser reconhecida como sendo variações que participariam de uma mesma coisa: muitas podem ser as virtudes, mas todas devem ser iguais em uma coisa - naquilo que as tornam uma virtude (Men. 72b 1-9), até aqui Sócrates; isto é dizer, o ser das diversas virtudes deriva e depende da Forma da Virtude ${ }^{2}$, a partir daqui, Platão. Ora, este ponto de ruptura e relação entre o pensamento socrático e o pensamento platônico assume um aspecto profundamente interessante no caso específico do diálogo Fédon: a superação dos limites da filosofia socrática, tal qual conhecida pela tradição, através daquele que é talvez o aspecto teorético mais importante atribuído à figura de Platão, qual seja, a Doutrina das Formas, é apresentado em um diálogo que narra justamente a morte de Sócrates. Daí a importância de perguntarmos: seria a morte de Sócrates a condição dramática/narrativa sine qua non para o estabelecimento de teses propriamente platônicas? Seria Fédon uma narrativa de cunho edipiano?

\section{II}

Voltemos a Doutrina das Formas. Segundo Erler (2013), isto posto, as Formas seriam, para Platão, os fundamentos que instanciam os fenômenos tais quais eles se manifestam:

2

Devemos estar aqui cientes de que Mênon é um diálogo da primeira fase, ainda em direção ao período intermediário, e portanto, a Doutrina das Formas não aparece aqui. Utilizamos o termo virtude e a relação com a forma da virtude apenas como exemplo ilustrativo e não em uma tentativa de afirmar que em Mênon tal seja a solução para o problema de uma definição de virtude - embora seja este o caso se pensarmos no Platão da fase intermediária. 
As ideias, portanto, são a resposta platônica à pergunta sobre como se pode esclarecer conceitos (universais) não apreensíveis empiricamente. Segundo Platão, as ideias são o fundamento pelo qual os fenômenos são assim como são (Euthyphr. 6d.) Quem quiser julgar, portanto, se uma ação é corajosa, piedosa ou moderada, ou quem quiser construir uma mesa, tem de voltar o "olho espiritual" de sua alma, retirando-o da multiplicidade das formas de aparição, para a ideia, que é sempre igual a si mesma e possui uma única forma. (ERLER, 2013, p. 223, grifos nossos).

Esta fala de Erler, conforme podemos logo perceber, é bastante significativa, pois permite já observar dois aspectos centrais a respeito das Formas se as pensarmos no modo como são concebidas em Fédon: (I) A prioridade ontológica e causal das Formas sobre a multiplicidade sensível - nas palavras de Kraut: "Uma conjectura provável é a de que a separação das formas a partir dos sensíveis consista em sua independência ontológica: eles existem independentemente de contarem com a participação de objetos sensíveis." (KRAUT, 2013, p. 33); e (II) As Formas, é claro, não são conhecidas através do sensível e da percepção do corpóreo, é preciso olhar para além da multiplicidade, para além do devir, para tal conhecimento é forçoso que se abra "o olho espiritual" de que falou Erler ${ }^{3}$. Ora, estes dois eixos já são o suficiente para notarmos de maneira clara e distinta como o itinerário intelectual platônico supera os limites impostos pela filosofia de Sócrates: pois embora as Formas surjam, podemos dizer, de uma demanda do pensamento socrático, Platão eleva tanto a demanda quanto a solução em si para um outro nível filosófico. Isto é dizer, Platão através de seu porta-voz em Fédon, sai das fronteiras de uma filosofia ética e moral para constituir, a partir de um problema que surge no âmbito de tais filosofias, uma ontologia. Nos parece que é precisamente neste mesmo espírito que Kraut enfatiza que:

Embora Sócrates tenha feito perguntas como "o que é virtude" - e de acordo com Aristóteles, ele foi o primeiro a se envolver nessa investigação - ele não mostrou nenhum interesse em uma série adicional de questões de segunda ordem que

3 No livro X da República, o Sócrates platônico afirmará a respeito da imortalidade da alma e de sua cognoscibilidade que: "[...] para conhecer bem sua verdadeira natureza, devemos considerá-la, não como fazemos presentemente, deformada pela sua união com o corpo e outras misérias, (mas) cumpre contemplá-la atentamente, com os olhos da razão, tal como ela é, quando é pura." (Rep. X, 611b 8 -611c 3, grifos nossos). Porém, se como veremos mais adiante em Fédon, há em Platão a defesa de uma relação profunda entre a alma imortal e o conhecimento das Formas, sendo que será à alma que caberá o conhecimento das Formas, talvez pudéssemos supor que o conhecimento destas também se desse pelo mesmo caminho, isto é, por este "olhar da razão" - o que nos remete ao "olho espiritual" de Erler. 
possa ser feita sobre objetos da questão que se está perguntando: aquilo que estamos buscando é algo que existe independentemente de seres humanos? É algo que possa ser detectado por meio dos sentidos? Pode mudar ou perecer? Como é possível aprendermos com isso? E quanto às relações com pessoas e atos que são corretamente consideradas virtuosas, mas não são idênticas ao que a virtude é? Como esses objetos do pensamento se relacionam entre si? (KRAUT, 2013 , p. 33, grifos nossos).

Ora, ao que tudo indica, sobretudo por aquilo que grifamos, Kraut parece seguir na mesma linha do que conjecturamos anteriormente sobre a fala de Erler e dos dois aspectos a respeito das Formas que elencamos, quais sejam, (I) sua prioridade ontológica e (II) sua incognoscibilidade através da percepção sensível. Agora bem, ambos os tópicos são minunciosamente abordados em Fédon - sendo tanto eles quanto as próprias Formas etapas cruciais da defesa platônica em prol da imortalidade da alma, defesa que só ganha sentido uma vez posto o contexto dramático/narrativo do diálogo: é porque Sócrates está morrendo que se torna interessante apresentar - e isso é dito ao longo de todo o diálogo uma prova para a imortalidade da alma e para a bem-aventurança dos filósofos no post mortem. Na presente reflexão, por fins metodológicos, nos ocuparemos sobretudo do segundo aspecto elencado por Erler, a saber, da incognoscibilidade das Formas através do sensível, pois cremos ser precisamente a partir deste aspecto que podemos melhor relacionar a dimensão dramática à dimensão teórica do diálogo. Porém, esclareçamos antes, embora de forma bastante sucinta, a natureza do primeiro aspecto.

\section{III}

Para compreendermos como se estabelece a prioridade ontológica das Formas em relação ao sensível, tanto em seu sentido causal quanto na sua independência para com aquilo que nelas participa, faremos uso do que Cristopher Shields (2011, p.379) chama de argumento "Um de Muitos" - pois é de maneira bastante próxima que o problema das Formas aparece em Fédon (especificamente em Féd. 74b-76e e 99a-105e). Podemos resumir este argumento nos seguintes termos: dado um conjunto de objetos, todos reconhecidos como sendo objetos de um mesmo tipo, digamos $f$, haveria um atributo $f$ - 
dade, que distinto e independente em sua existência dos objetos $f$, seria o próprio atributo $f$ dade a possibilidade da existência dos objetos $f$ enquanto sendo $f$, sem que o contrário fosse verdadeiro. Se utilizarmos termos como particulares e universal, poderíamos estabelecer, entendendo $f$-dade como um universal, uma dependência ontológica dos particulares $f$ em relação ao universal $f$-dade, uma vez que o particular $f$, enquanto uma manifestação do universal, obtém o seu ser à medida que participa no universal $f$-dade. Por exemplo: tudo o que é justo, o é conforme participa da Justiça em si; esta separada, imutável, eterna, causa de tudo aquilo que pode ser justo, sem que ela, enquanto tal, seja (ao passo que é uma existência) por existir uma miríade de entidades que sejam justas. Como Shields bem enfatiza: "É surpreendente quão rapidamente, com base somente na simples suposição de haver um traço comum a muitos particulares, este argumento nos leva às portas da concepção platônica das Formas.” (SHIELDS, 2011, p.380). Passemos agora ao segundo aspecto.

\section{IV}

Sem embargo, de modo a melhor compreender a maneira pela qual se veta ao corpo o conhecimento das Formas é necessário antes, e este é o itinerário presente em Fédon, entendermos como o Sócrates de Platão distingue o corpo e a alma a partir do problema da morte. Em Féd. 64a 5-10 Sócrates afirma enfaticamente que aqueles que dedicam suas vidas a filosofia nada fazem ao se dedicar a uma tal atividade a não ser se prepararem continuamente para a morte, de modo que uma vez sendo a filosofia uma postura para com o ser do indivíduo que se configuraria enquanto um ser-para-a-morte - i.e: a morte enquanto o horizonte através do qual o filósofo orienta sua vida, a morte enquanto o fim da filosofia -, seria contraditório, da parte de qualquer filósofo, diante do momento derradeiro, se revoltar contra sua sina. É por isso que Sócrates (Féd. 61e) recomenda que Eveno o siga em sua iminente empresa. Talvez, seja também em vista do mesmo motivo que Fédon, quem narra os momentos finais de Sócrates a Equécrates, insista do início ao fim que o filósofo se mostrara sereno até último suspiro. O herói dramático não poderia contradizer o que ensina o filósofo - diz Fédon: "Era por demais estranho o que eu sentia junto dele. Não podia lastimá-lo, como o faria perto de um ente querido no transe derradeiro. O Homem me parecia felicíssimo, Equécrates, tanto nos gestos como nas palavras, reflexo exato da intrepidez e da nobreza com que se despedia da vida." (Féd. 58 e, grifos nossos). 
Agora bem, para que se assimile o valor do que está em jogo com esta interpretação da postura filosófica - da morte como sendo o fim da filosofia -, precisamos estabelecer de antemão o que está sendo tomado por morte segundo a leitura platônica apresentada em Fédon através da persona socrática. Sócrates ali nos diz: "Que não será [a morte] senão a separação entre a alma e o corpo? Morrer, então, consistirá em apartar-se da alma o corpo, ficando este reduzido a si mesmo, e por outro lado, em libertar-se do corpo a alma e isolarse em si mesma? Ou será a morte outra coisa?" (Féd. 64c 4-7). A morte, portanto, passa, desde já, a ser compreendida nos termos de um dualismo: a alma que se liberta do corpo.

Uma vez a morte assim concebida, como uma separação entre corpo e alma, tornase claro o que Platão quer dizer por meio de Sócrates com a sua definição de filosofia como sendo uma "preparação para a morte": ora, não é isso, de fato, o que buscam os filósofos? Um refreamento das paixões do corpo? Um controle de seus vícios? Um afastamento de seus prazeres (Féd. 64d)? Não é o corpo que impede, quase sempre, a ascensão dos homens a uma vida virtuosa? Afinal, deve-se dizer com Sócrates, que "Nisto, por conseguinte, antes de mais nada, é que o filósofo se diferencia dos demais homens: no empenho de retirar quanto possível a alma da companhia do corpo.” (Féd. 65a 1-3). É, portanto, neste sentido, que a morte pode ser a realização da filosofia, posto que é necessariamente no total apartamento com o corpo que a sophia se torna enfim uma possibilidade factual. Consequentemente, nos diz a persona socrática,

[...] ao vires um homem revoltar-se no instante de morrer, não será isso prova suficiente de que não se trata de um amante da sabedoria, porém amante do corpo? Um indivíduo nessas condições também será, possivelmente, amante do dinheiro ou da fama, se não o for de ambos ao mesmo tempo. (Féd. 68c 1-4).

Contudo, e isto é o que mais nos interessa, não é apenas no âmbito das virtudes que o corpo pode ser um obstáculo: ele possui também um valor epistemologicamente negativo. Em Féd. 65b vemos Sócrates apresentar uma dúvida epistêmica a respeito da percepção sensível: os sentidos além de serem insuficientes para garantir a verdade a respeito do múltiplo e diverso reino do devir são também uma fonte de erro. Isto é dizer, o corpo não pode ser fundamento do conhecimento, ao contrário, é, antes, uma obstrução (Féd. 65c) ao itinerarium mentis in veritatem ${ }^{4}$. É por isso que se torna dever do filósofo desprezar o

4 "O caminho da mente em direção a verdade", recorremos a esta expressão aqui em referência ao pensamento de Alexandre Koyré quem a utiliza em vista de sua análise intelectual da história filosófica do pensamento. A expressão 
corpo e buscar sempre se isolar em sua alma (Féd. 65d), pois é a ela, ao pensamento, que cabe a pretensão de conhecimento da verdade. Segundo fala o Sócrates de Platão:

Ora, a alma pensa melhor quando nada disso tem a perturbá-la, nem a vista, nem o ouvido, nem dor nem prazer de espécie alguma, e concentrada ao máximo em si mesma, dispensa a companhia do corpo, evitando tanto quanto possível qualquer comércio com ele, e esforça-se por apreender a verdade. (Féd. 65c 5-9).

Será justamente em torno desta temática que em Féd. 65d 4-5, pela primeira vez em Fédon, as Formas se tornam parte do problema filosófico em debate. Para este Sócrates platônico, uma vez concedida a possibilidade de coisas como o Justo em si, o Belo em si e o Bem em si serem de fato alguma coisa existente, fica a questão a se saber se é possível conhecer tais entes através da percepção sensível. Ora, já vimos que o corpo é um obstáculo ao conhecimento da verdade, e se retomamos a fala de Erler $(2013,223)$ sobre o papel ontológico das Formas enquanto instanciadoras da realidade, tudo nos levaria a crer na incognoscibilidade das Formas através do sensível. Pelo contrário, seria somente por meio do pensamento, pensante em si e afastado do corpóreo, que se poderia atingi-las - a alma, e só ela, pensando, poderia ascender à verdade do ser, posto ser o corpo antes um fator de pertubação do que qualquer outra coisa (Féd. 66 b). E mais: um corpo, enquanto matéria corruptível, corrompe a alma e como tal, impediria a busca da filosofia, qual seja, a busca ainda de todo verdadeiro filósofo: a verdade. Assim, nem pela visão nem por nenhum outro sentido corpóreo as Formas podem ser percebidas, mas somente através da alma é que se pode conhecer o Bem em si, o Belo em si, o Justo em si e assim por diante:

Refiro-me a tudo: grandeza, saúde, força e o mais que for, numa palavra: à essência de tudo o que existe, conforme cada coisa. É por intermédio do corpo que percebemos o que neles há de verdadeiro, ou tudo se passará da seguinte maneira: quem de nós ficar em melhores condições de pensar em si mesmo o mais exatamente possível o que propõe examinar, não é esse que estará mais perto do conhecimento de cada coisa? Ou não? (Féd. 65e 1-7).

nos parece bastante adequada no contexto da obra de Platão posto que também aqui, é a mente que se encontra em um itinerário para a verdade. A busca pela verdade, seja para Koyré, seja para Platão, é uma busca intelectual, cabe antes aos "olhos da alma" que a bruta experiência do corpo. Não por menos Koyré lê a Revolução Científica dos Séculos XVI e XVII, aonde a matematização da física e a dúvida epistemológica dos sentidos teve um papel crucial, como sendo uma Desforra de Platão. Cf: KOYRÉ, A. Galileu and Plato in: Journal of the History of Ideas. Vol. 4, No. 4. Pennsylvania: University of Pennsylvania Press, $1943 . \quad$ p.400-428. $\quad$ Disponível em:

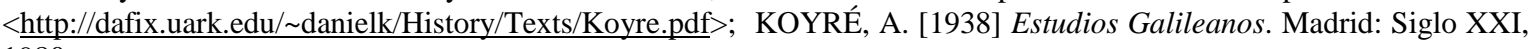
1980. 
Um pouco mais a frente no diálogo (Féd.76e), a persona socrática retoma essa relação entre as Formas e a alma a partir da cognoscibilidade exclusiva daquelas por meio desta. Após um longo argumento em defesa da imortalidade da alma através da teoria da reminiscência (a partir de Féd. 74b) - no presente diálogo, ao contrário do que é visto em Mênon, tal teoria é fundamentalmente interseccionada pela Doutrina das Formas - e uma vez demonstrada que a existência e o conhecimento das Formas é anterior ao nascimento (isto é, a união da alma com um corpo), é forçoso que a própria alma fosse também anterior ao nascimento, já que é a ela que compete a capacidade de conhecer as Formas, cujo conhecimento, embora possa ter sido esquecido, é manifesto pela maneira como nos referimos e comparamos as coisas sensíveis. Como insiste Sócrates:

Se existe, realmente, tudo isso com que vivemos a encher a boca: o belo e o bem e todas as essências desse tipo, e se a elas referimos tudo o que nos chega por intermédio dos sentidos, como algo preexistente, que encontramos em nós mesmos e com que o comparamos: será forçoso que, assim como elas, exista nossa alma antes de nascermos. (Féd. 76d-e).

Logo se vê, a alma e as Formas estão diretamente vinculadas. Em Féd. 78b tem-se início o argumento em defesa da imortalidade da alma que visa refutar um certo temor de Símias e de Cebes - os dois principais personagens com quem Sócrates trava dialogo na narrativa de Fédon - a saber: a possibilidade da alma se dispersar no momento da morte do corpo, e com isso, dela também perecer. Esse argumento é bastante importante para melhor esclarecer como a alma está relacionada ao eterno e ao imutável ao passo que ao corpo cabe as relações com o devir. Ora, nos diz Sócrates (Féd. 78c): é antes ao composto que compete a possibilidade da dispersão. É ele, o composto, que se adequa à fluidez, à multiplicidade, à mudança, à alteração. Aquilo que não é composto, o simples, por sua vez, é estático, imutável, como é o caso das Formas (Féd. 78d), sempre iguais, sempre idênticas a si, eternas, puras e imutáveis. Agora bem, não é condizente com as Formas a dispersão ou a alteração, é ao devir, ao sensível, ao diverso, que cabe essa variação no ser. O que nos permite concluir, juntamente a Sócrates, e nos perguntamos se quanto a essas coisas sensíveis, se não "[....] se podem ver e tocar ou perceber por intermédio de qualquer outro sentido, ao passo que as essências, que se conservam sempre iguais a si mesmas, só podem ser apreendidas pelo raciocínio, por serem todas elas invisíveis e estarem fora do alcance 
da visão?" (Féd. 79a 1-3). Portanto, a alma não se dispersa no momento da morte porque não só ela não é um composto como ela se relaciona com aquilo que é ontologicamente mais simples, mais eterno, mais imutável, aquilo ao que lhe cabe, e somente a ela, o conhecimento: as Formas. Kraut parece seguir pela mesma linha interpretativa que adotamos, posto que diz o filósofo americano:

A separação entre corpo e alma é tema investigado com mais detalhes no Fédon [...] e no Fédon, vemos o quanto continua a crescer o interesse de Platão por terrenos que Sócrates deixara ou inexplorados ou pouco desenvolvidos. Aqui, pela primeira vez nos escritos de Platão, encontramos declaração e argumentos decisivos de que existe um reino de objetos completamente diferentes daqueles que nos são familiares: esses objetos são imutáveis (78d) e nos são revelados pelo pensamento em vez de pela sensação (79d), sendo diferentes a um só tempo de corpo e alma (79 b-c), e duram para sempre (79d). (KRAUT, 2013, 29-31, grifos nossos).

Tudo o que consideramos até aqui nos permite perceber e sistematizar uma sequência de pares opostos que se vinculam entre si no interior do diálogo platônico em questão: Formas - Devir; alma - corpo; invisível - visível; divino - mortal; eterno perecível, imutável - mutável; incorruptível - corruptível. Facilmente percebemos, que a partir de uma tal polarização é como se a alma pertencesse, se assemelhasse e se relacionasse com uma dimensão do ser radicalmente oposta àquela a qual pertence o corpo - como se pertencessem a reinos ontológicos distintos. E deste modo, a compreensão tanto da imortalidade da alma quanto do objeto cujo conhecimento é uma demanda da alma torna-se fundamentalmente importante para que entendamos o papel das Formas no interior do pensamento platônico, entender como este grupo de entidades se relaciona com o sensível e em que esfera própria do ser se alocam. É afinal, nessa relação da alma com o eterno, com o imutável, em suma, com as Formas, que a sabedoria se define: 
[... ] quando ela [a alma] examina sozinha alguma coisa, volta-se para o que é puro, sempiterno, imortal e que sempre se comporta do mesmo modo, e, por lhe ser aparentada, vive com ele enquanto permanecer consigo mesma e lhe for permitido, deixando, assim, de divagar e pondo-se em relação com o que é sempre igual e imutável, por estar em contato com ele. A esse estado, justamente, é que damos o nome de sabedoria. (Féd. 79d 1-7, grifos nossos).

É interessante então notar que elementos teoréticos tão fundamentais como a Doutrina das Formas e a distinção entre alma e corpo só apareçam em Fédon ${ }^{5}$ em função de um sentido dramático: a imortalidade da alma, seus vínculos com as Formas, sua distinção em relação ao corpo, em suma, toda esta rede conceitual platônica, só se tornam pertinentes à medida que a morte se manifesta enquanto sendo a chave temática em torno da qual a discussão filosófica é assumida - é o problema da morte que os convoca. Problema que em Fédon surge, sabemos, do contexto dramático da narrativa. Como bem diz o porta-voz platônico (Féd. 61e 1-3): é aos que se encontram na iminência de sua sina que cumpre filosofar a respeito do pós-vida. À guisa de conclusão, poderíamos acrescentar metaforicamente: é porque Sócrates aqui vai morrer que pôde Platão superar a sua filosofia.

\section{Referências}

ERLER, M. Platão. Trad. Enio Paulo Giachini. Brasília: EDU-UNB, 2013.

KRAUT, R. Introdução ao estudo de Platão. In: KRAUT, Richard (org.). Platão. Aparecida: Ideias \& Letras, 2013. pp. 15-68.

PELLAUER, David. Compreender Ricoeur. Petrópolis: Vozes, 2009.

PLATÃo Fédon. Texto grego J. Burnet; Trad. Carlos Alberto Nunes. Ed. Bílingue. Bélem: ed.ufpa, 2011.

5

Diálogo que tornou-se conhecido pela tradição como o principal lugar onde Platão teria delineado tais doutrinas. 
A República. Trad. J. Guinsburg. Introdução de Maria Sylvia Carvalho Franco. São Paulo: Perspectiva, 2016.

. Mênon. Texto estabelecido e anotado por John Burnet. Trad Maura Iglésias. São Paulo: Folha de S. Paulo, 2015.

RICOEUR, Paul. Teoria da Interpretação. Introdução e comentários de Isabel Gomes. Lisboa: Porto Editora, 1995.

SHIELDS, C. Aprendendo sobre Platão com Aristóteles. In: Benson, H.H. (org.). Platão. Porto Alegre: Artmed, 2011. p. 376-388. 